\title{
LEVANTAMENTO FLORÍSTICO E FITOSSOCIOLÓGICO DE PLANTAS DANINHAS: UMA REVISÃO DOS MÉTODOS ENCONTRADOS
}

\author{
Fábio Henrique Krenchinski* \\ Leandro Paiola Albrecht** \\ Victor José Salomão Cesco**** \\ Danilo Morilha Rodrigues ${ }^{* * * *}$ \\ Juliano Cordeiro******
}

\begin{abstract}
RESUMO: Este trabalho teve por objetivo conhecer, apresentar e analisar métodos de avaliação da composição florística e fitossociológica de plantas daninhas das principais culturas agrícolas, baseando-se em dados bibliográficos de diversos autores, dentro da literatura pertinente. Além dos cálculos específicos, como densidade e frequência, outros métodos de análise fitossociológica foram considerados quando utilizados nos levantamentos sobre a ocorrência de plantas daninhas de interesse econômico na literatura e também a variabilidade de métodos que podem ser utilizados para a condução do trabalho a campo do manejo de plantas daninhas. É recomendável que o trabalho de identificação de plantas daninhas seja feito após a colheita, onde a infestação é maior e a riqueza é considerável, outrora, a identificação de plantas muda de acordo com a cultura implantada seja perene ou anual. Várias outras cultivares podem ser avaliadas em períodos diferentes do recomendado como, por exemplo, o feijão-caupi, avaliado na fase vegetativa, e o guaraná, avaliado por idade das plantas. Os métodos de avaliação variam muito de autor para autor, o que torna difícil a escolha e padronização de um método para a avaliação florística e fitossociológica das plantas invasoras, dentro de um contexto do MIPD (manejo integrado de plantas daninhas) e na geração de resultados científicos. Tal retrato caracteriza a diversidade e complexidade dos agroecossitemas, dentro do contexto dos sistemas produtivos, e aponta para a necessidade de mais estudos.
\end{abstract}

PALAVRAS CHAVE: Florística; Métodos; Plantas Daninhas; Variabilidade.

\footnotetext{
"Discente de agronomia pela Universidade Federal do Paraná - UFPR, Campus Palotina, (PR), Brasil; E-amil: fabiohk2@gmail.com

** Docente adjunto da Universidade Federal do Paraná - UFPR, Campus Palotina, (PR), Brasil

*** Universidade Federal do Paraná - UFPR, Campus Palotina, (PR), Brasil

***** Universidade Federal do Paraná - UFPR, Campus Palotina, (PR), Brasil;

******* Docente adjunto da Universidade Federal do Paraná, Brasil
} 


\title{
FLORISTIC AND PHY TOSOCIOLOGICAL SURVEY OF WEEDS: A REVIEW OF METHODS EMPLOYED
}

\begin{abstract}
Current survey aims at knowing, presenting and analyzing the evaluation methods of the floristic and phytosociological composition of weeds from the main agricultural environment. It is based on bibliographical data from several authors within the extant literature. Besides specific methods, such as density and frequency, other phytosociological methods were investigated when used in the survey on the occurrence of economically interesting weeds mentioned in the literature and also in the variability of methods that may be employed on the field for weed management. It should be recommended that weed identification may be done after harvest since during this period infestation is highest and richness abounds. Plant identification changes according to perennial or annual culture. Several cultivars should be evaluated during different periods than those recommended, such as the caupi-beans, evaluated during the vegetative phase, and guaraná, evaluated by the plant's age. Evaluation method vary according to authors and it is rather difficult to select and standardize a method for the floristic and phytosociological evaluation of invading plants within the integrated management of weeds, and in the production of scientific results. The above characterizes the diversity and complexity of agroecosystems within the context of production systems. Further studies are required.
\end{abstract}

KEY WORDS: Floristics; Methods; Weeds; Variability.

\section{INTRODUÇÃO}

As plantas daninhas impedem ou dificultam a máxima produtividade das culturas. No milho podem provocar redução da altura de inserção da primeira espiga, o comprimento e a circunferência das espigas, o peso das espigas e dos grãos e a produtividade da cultura, independente do cultivar (KOZLOWSKI, 2002; ROSSI et al., 1996). Na cultura da soja a interferência das daninhas diminui a área foliar e o peso dos grãos (MEROTTO et al., 2002; SILVA et al., 2009).

Uma das primeiras etapas para um manejo adequado de plantas daninhas em áreas de cultivo envolve a identificação das espécies invasoras, especialmente daquelas que apresentam maior importância na estrutura da comunidade, para posterior tomada de decisão referente ao melhor manejo a ser adotado, seja ele cultu- 
ral, mecânico, físico, biológico ou químico, e/ou ainda, o estabelecimento de uma ordem de prioridade de erradicação dentre as espécies presentes para que seja determinado um programa de controle (KUVA et al., 2007; OLIVEIRA; FREITAS, 2008; YANAGIZAWA; MAIMONI-RODELLA, 1999).

Além disso, a identificação botânica das espécies invasoras é importante na obtenção do conhecimento específico sobre suas populações e biologia dessas plantas (MASCARENHAS et al., 2009), pois, é comum encontrar variações em sua morfologia de acordo com ambiente que ocorrem (OLIVEIRA; FREITAS, 2008).

Para conhecer as espécies de uma determinada área utiliza-se o levantamento florístico seguido da correta identificação taxonômica dos espécimes encontrados. Essa metodologia possibilita a análise qualitativa das plantas que pode ser complementada com estudo fitossociológico (BRAUN-BLANQUET, 1979), visando fornecer dados como densidade de plantas daninhas, abundância e a sua relação com a população total infestante. $\mathrm{O}$ método fitossociológico nos permite fazer várias inferências como, por exemplo, ocorrência e abundância da flora das plantas invasoras (ERASMO et al., 2004).

As informações qualitativas obtidas nos levantamentos florísticos podem ser apresentadas de forma a verificar a ocorrência ou não de relações entre as espécies encontradas e a área de estudo. O método quantitativo procura descrever a estrutura da comunidade de plantas através do número de indivíduos e a densidade por unidade de área amostrada das espécies encontradas (CAUSTON, 1988).

A realização de estudos fitossociológicos pode auxiliar na comparação de diferentes espécies em um determinado momento e espaço, no qual é importante a repetição programada dos estudos, pois ele pode indicar variações da importância de uma espécie ou uma população, e essas variações podem estar relacionadas com as práticas agrícolas empregadas (OLIVEIRA; FREITAS 2008; PITELLI, 2000).

Uma vez que as comunidades infestantes podem variar sua composição e estrutura em função do tipo e da intensidade de tratos culturais como preparo do solo (JAKELAITIS et al., 2003), uso de rotação de culturas (BALBINOT et al., 2008), o reconhecimento das espécies é fundamental quando for levado em conta o custo financeiro e ambiental da utilização de produtos químicos. Dessa maneira, é importante investir em métodos que auxiliem no conhecimento dessas comunidades (ERASMO et al., 2004). 
Após a identificação das plantas daninhas, o levantamento fitossociológico passa por cálculos propostos por Mueller-Dombois e Ellemberg (1974): esses cálculos são de densidade, densidade relativa, frequência, frequência relativa, abundância, abundância relativa e o valor de importância relativa.

Apresentando a relevância da composição florística e do levantamento fitossociológico no MIPD (manejo integrado de plantas daninhas) e entendendo que após amostragem os cálculos propostos e utilizados pouco diferem, porém, constatando a diversidade no tocante a princípios, procedimentos e métodos amostrais, torna-se necessário uma revisão critica dos mesmos. Nessa percepção, este trabalho teve por objetivo realizar o levantamento bibliográfico sobre os métodos de avaliação da ocorrência das plantas daninhas em áreas de cultivo agrícola citadas em levantamentos florísticos e fitossociológicos, e analisar as possíveis implicações da existência de distintos procedimentos.

\section{METODOLOGIA}

A metodologia utilizada consistiu, em um primeiro momento, em realizar uma busca em trabalhos publicados em periódicos indexados sobre plantas daninhas infestantes em culturas de interesse econômico. Em seguida foram analisados os diversos procedimentos e métodos empregados, tanto para a caracterização florística como fitossociológica das comunidades de plantas daninhas, bem como os cálculos empregados para a obtenção dos parâmetros de fitossociologia, observando que foram catalogados e analisados os métodos dentro do contexto da pesquisa científica e úteis no MIPD.

\section{RESULTADO E DISCUSSÃO}

A maioria dos trabalhos que foram realizados utilizou o estudo sobre a composição florística e o levantamento fitossociológico da área.

Geralmente, os estudos de fitossociologia de comunidades infestantes são realizados em uma fase determinada da cultura, normalmente próximo à colheita, 
quando teoricamente a infestação daninha é maior (ADEGAS et al., 2010). Porém o mesmo autor observa que o período crítico de prevenção à interferência (PCPI) das plantas daninhas com as culturas, geralmente promove perdas antes mesmo do final do ciclo da cultura. Embora seja este o período indicado, variações existem de acordo com o objetivo do pesquisador, podendo ser verificadas análises antes mesmo do plantio, em períodos vegetativos, pré-colheita, e mesmo após a colheita das culturas (Quadro 1).

Após a identificação das plantas daninhas, o levantamento fitossociológico passa por cálculos propostos por Mueller-Dombois e Ellemberg (1974); esses cálculos são de densidade, densidade relativa, frequência, frequência relativa, abundância, abundância relativa e índice de valores de importância relativa, obtidos através das seguintes fórmulas:

Densidade $(\mathrm{De})=\underline{\mathrm{n}^{\mathrm{o}} \text { total de indivíduos por espécie }}$ área total coletada

Densidade relativa $($ Der $)=\frac{\text { densidade da espécie } \quad X \quad 100}{\text { densidade total de todas as espécies }}$

Frequência (Fre) $=\underline{\mathrm{n}^{0}}$ de quadrados que contém a espécie área total coletada

$$
\text { Frequência relativa }(\text { Frer})=\frac{\text { frequência da espécie } \times 100}{\text { frequência total de todas as espécies }}
$$

Abundância $(\mathrm{Ab})=\frac{\mathrm{n}^{\mathrm{o}} \text { total de indivíduos por espécie }}{\mathrm{n}^{\mathrm{o}} \text { total de quadrados que contém a espécie }}$

Abundância relativa $(\mathrm{Abr})=\underline{\text { abundância da espécie } \quad \mathrm{X} \quad 100}$ abundância total de todas as espécies

Índice de Valores de Importância Relativa (I.V.I.) = frequência relativa (Frer)

$$
+ \text { densidade relativa (Der) }+ \text { abundância relativa (Abr). }
$$


Os métodos de avaliação são criteriosos tanto para a composição florística quanto para o levantamento fitossociológico (BRAUN-BLANQUET, 1979), com metodologias de cálculos bem consolidadas e amplamente difundidas, utilizadas e aceitas pela comunidade acadêmica.

O método mais empregado para avaliação fitossociológica, dentro do procedimento amostral, foi o de quadrado inventário. O método do quadrado inventário consiste em analisar a flora de plantas daninhas em uma determinada área por meio de identificação e contagem das espécies.

Conforme a Quadro 2 o tamanho do quadrado inventário varia de acordo com os autores que realizam as pesquisas e os métodos por eles empregados. $\mathrm{O}$ mesmo acontece com a forma de lançamento do quadrado ou procedimento amostral, que é adaptado para cada situação de experimento. O número de amostragens também é adaptado para cada situação em que o experimento é conduzido, variando de poucas vezes até um número bem elevado das mesmas. De qualquer forma, predominam tamanhos em torno de $0,5 \times 0,5$. Estudos do componente herbáceo de ambientes naturais usam valores de unidades de amostragem que variam entre $0,5 \mathrm{e}$ $1 \mathrm{~m}$ de lado (parcelas de amostragem).

Quadro 1. Diversidade no levantamento e registro de plantas daninhas em diferentes períodos e culturas estudadas

\begin{tabular}{|l|l|l|l|}
\hline Cultura & Estado & Período* & Estudo \\
\hline Guaraná & Amazonas & Plantas com 4 a 8 anos & ALBERTINO et al., 2008 \\
\hline Feijão - Caupi & Maranhão & Fase vegetativa & MARQUES et al., 2010 \\
\hline Pastagem & Amazonas & Sob Pastejo & GALVÃO et al., 2010 \\
\hline Arroz - sequeiro & Maranhão & $\begin{array}{l}\text { Fase vegetativa e pós-col- } \\
\text { heita }\end{array}$ & CORRÊA et al., 2010 \\
\hline Algodão & Ceará & 15,30 e 60 DAE*** & PEREIRA et al., 2008 \\
\hline Milho & Goiás & Fase vegetativa & $\begin{array}{l}\text { FONTES; SHIRATSUCHI, } \\
\text { 2005 }\end{array}$ \\
\hline Arroz - irrigado & Tocantins & Antes do plantio & ERASMO et al., 2004 \\
\hline Cana-de-açúcar & Rio de Janeiro & Cana-planta e cana-Soca & OLIVEIRA; FREITAS, 2008 \\
\hline Girassol & MS, GO e RS & 20 e 40 DAE & ADEGAS et al., 2010 \\
\hline
\end{tabular}


(conclusão)

\begin{tabular}{|l|l|l|l|}
\hline Mandioca & Rio de Janeiro & 6 meses AP*** & HUZIWARA et al., 2009 \\
\hline Pinhão Manso & Tocantins & 3 anos de cultivo & DOTTO et al., 2010 \\
\hline Sorgo granífero & Minas Gerais & Pré-colheita & $\begin{array}{l}\text { DOMINGOS; LACA-BUEN- } \\
\text { DIA, 2010 }\end{array}$ \\
\hline Banana & São Paulo & Em plena produção & GOMES et al., 2010 \\
\hline Soja & São Paulo & 14,28 e 35 DAE & PEREIRA, 2000 \\
\hline
\end{tabular}

* Época, idade e condição em que a cultura se encontrava. ** Dias após a emergência. *** Após o plantio.

O grande problema destas várias formas de avaliação é que se torna difícil escolher um método eficiente de análise para realização de novos trabalhos, levando muitos autores interessados na área a adaptar novas técnicas para uma coleta eficiente. Outra desvantagem seria a impossibilidade de comparação entre trabalhos publicados na mesma cultura. Cita-se também, uma implicação prática, que seria a dificuldade de padronizar procedimentos metodológicos no âmbito do campo, dentro de um MIPD.

Quadro 2. Variabilidade de tamanhos de quadrado inventário dos trabalhos analisados e o método amostral utilizado (continua)

\begin{tabular}{|c|c|c|c|}
\hline Autores & $\begin{array}{l}\text { Tamanho do quadra- } \\
\text { do inventário }\end{array}$ & Plano amostral & $\begin{array}{l}\text { Número de amostra- } \\
\text { gens na área }\end{array}$ \\
\hline GALVÃO et al. (2011) & \multirow{4}{*}{$\begin{array}{c}1,00 \mathrm{~m} \times 1,00 \mathrm{~m}= \\
1,00 \mathrm{~m}^{2}\end{array}$} & $\begin{array}{l}\text { Lançamento ao acaso } \\
\text { em zigue- zague }\end{array}$ & $\begin{array}{c}62 \text { vezes em duas } \\
\text { áreas }\end{array}$ \\
\hline $\begin{array}{c}\text { DOMINGOS; } \\
\text { LACA-BUENDIA } \\
(2010)\end{array}$ & & \multirow{3}{*}{ Lançamento ao acaso } & 20 vezes \\
\hline $\begin{array}{l}\text { OLIVEIRA; FREITAS } \\
\text { (2008) }\end{array}$ & & & 30 vezes \\
\hline ADEGAS et al. (2010) & & & $\begin{array}{c}1118 \text { divididos em } 3 \\
\text { estados }\end{array}$ \\
\hline PEREIRA et al. (2000) & \multirow{2}{*}{$\begin{array}{c}0,50 \mathrm{~m} \times 0,50 \mathrm{~m}= \\
0,25 \mathrm{~m}^{2}\end{array}$} & Área útil da parcela & $\begin{array}{c}10 \text { vezes por parcela } \\
\text { (8 parcelas) }\end{array}$ \\
\hline GOMES et al. (2010) & & Lançamento ao acaso & 20 e 36 vezes \\
\hline
\end{tabular}


(conclusão)

\begin{tabular}{|c|c|c|c|}
\hline $\begin{array}{c}\text { ALBERTINO et al. } \\
(2008)\end{array}$ & $\begin{array}{c}0,60 \mathrm{~m} \mathrm{X} 0,60 \mathrm{~m}= \\
0,36 \mathrm{~m}^{2}\end{array}$ & $\begin{array}{c}\text { Duas linhas transver- } \\
\text { sais em forma de X } \\
\text { ao acaso }\end{array}$ & 20 vezes \\
\hline $\begin{array}{c}\text { MARQUES et al. } \\
(2010)\end{array}$ & $\begin{array}{c}0,50 \mathrm{~m} \mathrm{X} 0,30 \mathrm{~m}= \\
0,15 \mathrm{~m}^{2}\end{array}$ & Dentro da parcela & $\begin{array}{c}2 \text { vezes por parcela }(9 \\
\text { parcelas })\end{array}$ \\
\hline
\end{tabular}

\section{CONSIDERAÇÕES FINAIS}

O desenvolvimento de métodos para análise de plantas daninhas a campo se torna uma opção adicional ao agricultor e essencial ao pesquisador, pois auxilia em um controle das mesmas e até mesmo a identificação padrão de plantas em uma determinada região ou local. O levantamento florístico e o entendimento da fitossociologia dos agroecossitemas são fundamentais no manejo integrado de plantas daninhas (MIPD), o qual é quesito imprescindível na busca de sustentabilidade dos sistemas produtivos. Diante da grande variabilidade de métodos de amostragem de plantas daninhas, sugerido por diferentes autores, se torna complexa uma padronização para a obtenção dos dados e a escolha de um método mais preciso entre os diversos existentes. No entanto, a diversidade para procedimentos de diagnóstico fitossociológico torna evidente a diversificação e distinção dentro e entre os sistemas produtivos, apontando também a necessidade de mais estudos na área.

\section{REFERÊNCIAS}

ADEGAS, F. S. et al. Levantamento fitossociológico de plantas daninhas na cultura do girassol. Planta Daninha, v. 28, n. 4, p. 705-716, 2010.

ALBERTINO, S. M. F. et al. Composição florística das plantas daninhas na cultura de guaraná (Paullinia cupana), no estado do Amazonas. Planta Daninha, v. 22, n. 3, p. 351-358, 2004.

BALBINOT JR., A. A. et al. Formas de uso do solo no inverno e sua relação com a 
infestação de plantas daninhas em milho (Zea mays) cultivado em sucessão. Planta Daninha, v. 26, n. 3, p. 569-576, 2008.

BRAUN-BLANQUET, J. Fitosociología, bases para el estudio de las comunidades vegetales. Madrid: H. Blume, 1979. 820 p.

CAMPOS, J. B.; SOUZA, M. C. Potencial for natural forest regeneration from seed bank in an upper Paraná river floodplain, Brazil. Brazilian Archives of Biology and Technology. v. 46, n. 4, p. 625-639, 2003.

CARMONA, R. Problemática e manejo de bancos de sementes de invasoras em solos agrícolas. Planta daninha, v. 10, n.1/2, p. 5-16, 1992.

CARMONA, R. Banco de sementes e estabelecimento de plantas daninhas em agroecossistemas. Planta Daninha, v. 13, n. 1, 1995.

CAUSTON, D. R. An introduction to vegetation analysis, principles and interpretation. London: Unwin Hyman, 1988. 342 p.

CORRÊA, M. J. P. et al. Composição florística das plantas daninhas na cultura do arroz no município de Santa Luzia - MA. In: CONGRESSO BRASILEIRO DA CIÊNCIA DAS PLANTAS DANINHAS, 27., 2010, Ribeirão Preto. Anais... Londrina, PR: SBCPD, 2010.

DOMINGOS, M. K. R.; LACA-BUENDIA, J. P. Levantamento fitossociológico das plantas daninhas na pré-colheita da cultura do sorgo granífero em Uberaba - MG. FAZU em Revista, n. 7, p. 68-72, 2010.

DOTTO, M. C. et al. Levantamento fitossociológico de plantas daninhas em uma área de cultivo de pinhão manso (Jatropha curcas L.). In: CONGRESSO BRASILEIRO DA CIÊNCIA DAS PLANTAS DANINHAS, 27., 2010, Ribeirão Preto. Anais... Londrina, PR: SBCPD, 2010.

ERASMO, E. A. L.; PINHEIRO, L. L. A.; COSTA, N. V. Levantamento fitossociológico das comunidades de plantas infestantes em áreas de produção de arroz irrigado cultivado sob diferentes sistemas de manejo. Planta Daninha, v. 22, n. 2, p. 195-201, 2004. 
FONTES, J. R. A.; SHIRATSUCHI, L. S. Levantamento florístico de plantas daninhas em lavoura de milho cultivada no Cerrado de Goiás. Embrapa, Boletim de pesquisa e desenvolvimento 144, 2005.

GALVÃO, A. K. L. et al. Composição florística de plantas daninhas em pastagens no município de Parintins, AM. In: CONGRESSO BRASILEIRO DA CIÊNCIA DAS PLANTAS DANINHAS, 27., 2010, Ribeirão Preto. Anais... Londrina, PR: SBCPD, 2010.

GALVÃO, A. K. L. et al. Levantamento fitossociológico em pastagens de várzea no estado do Amazonas. Planta Daninha, v. 29, n. 1, p. 69-75, 2011.

GOMES, G. L. G. C. et al. Cadastramento fitossociológico de plantas daninhas na bananicultura. Planta Daninha, v. 28, n. 1, p. 61-68, 2010.

HUZIWARA, E. et al. Banco de sementes de plantas daninhas na cultura da mandioca na região norte do estado do Rio de Janeiro. In: CONGRESSO BRASILEIRO DE MANDIOCA, 13., 2009, Botucatu, SP. Anais... Botucatu, SP: UNESP, 2009.

IPARDES. Perfil das regiões geográficas: Oeste do Paraná. 2009. Disponível em: $<$ www.ipardes.gov.br > . Acesso em: 15 jul. 2011.

IKEDA, F. S. et al. Caracterização florística de bancos de sementes em sistemas de cultivo lavoura-pastagem. Planta Daninha, v. 25, n. 4, p. 735-745, 2007.

JAKELAITIS, A. et al. Dinâmica populacional de plantas daninhas sob diferentes sistemas de manejo nas culturas de milho e feijão. Planta Daninha, v. 21, n. 1, p. 71-7. 2003.

KOZLOWSKI, L. A. Período crítico de interferência das plantas daninhas na cultura do milho baseado na fenologia da cultura. Planta Daninha, v. 20, n. 3, p. 365-372, 2002.

KUVA, M. A. et al. Fitossociologia de comunidades de plantas daninhas em agroecossistema de cana crua. Planta Daninha, v. 25, n. 3, p. 501-511, 2007.

MARQUES, L. J. P. et al. Composição florística de plantas daninhas na cultura do feijão-caupi no sistema de capoeira triturada. Planta Daninha, v. 28, Número Especial, p. 953-961, 2010. 
MARTINS, F. R.; SANTOS, F. A. M. Técnicas usuais de estimativa da biodiversidade. R. Holos, v. 1, p. 236-267, 1999.

MASCARENHAS, M. H. T. et al. Flora infestante em pastagem degradada sob recuperação, pelo sistema de integração lavoura-pecuária, em região de cerrado. R. Bras. Milho Sorgo, v. 8, n. 1, p. 41-55, 2009.

MONQUERO, P. A. et al. Monitoramento do banco de sementes de plantas daninhas em áreas com cana-de-açúcar colhida mecanicamente. Planta Daninha, v. 29, n. 1, p. 107-119, 2011.

MONQUERO, P. A.; CHRISTOFFOLETI, P. J. Dinâmica do banco de sementes em áreas com aplicação freqüente do herbicida glyphosate. Planta Daninha, v. 21, n. 1, p. 63-69, 2003.

MUELLER-DOMBOIS, D.; ELLEMBERG, H. Aims and methods of vegetation eco$\log$ y. New York: John Willey \& Sons, 1974. 547 p.

OLIVEIRA, A. R.; FREITAS, S. P. Levantamento fitossociológico de plantas daninhas em áreas de produção de cana-de-açúcar. Planta Daninha, v. 26, n. 1, p. 33-46, 2008.

PEREIRA, E. S. et al. Avaliações qualitativas e quantitativas de plantas daninhas na cultura da soja submetida aos sistemas de plantio direto e convencional. Planta Daninha, v. 18, n. 2, 2000.

PEREIRA, J.R. et al. Composição florística de plantas daninhas em área cultivada com algodão herbáceo, submetidos a diferentes tratamentos herbicídicos. [s.1.]: Embrapa Algodão, 2008. 29p. (Boletim de Pesquisa e Desenvolvimento, 88).

PITELLI, R. A. Estudos fitossociológicos em comunidades infestantes de agroecossistemas. J. Conseb, v. 1, n. 3, p. 1-7, 2000.

ROSSI, I. H. et al. Interferência das plantas daninhas sobre algumas características agronômicas e a produtividade de sete cultivares de milho. Planta Daninha, v. 14, n. 2, 1996 .

SEVERINO, J. F.; CHRISTOFFOLETI, P. J. Banco de sementes de plantas daninhas em 
solo cultivado com adubos verdes. Bragantia, v. 60, n. 3, p. 201-204, 2001.

SILVA, A.F. et al. Interferência de plantas daninhas em diferentes densidades no crescimento da soja. Planta Daninha, v. 27, n. 1, p. 75-84, 2009.

SILVA, D. S. M.; DIAS-FILHO, M. B. Banco de sementes de plantas daninhas em solo cultivado com pastagens de Brachiaria brizantha e Brachiaria bumidicola de diferentes idades. Planta Daninha, v. 19, n. 2, p. 179-185, 2001.

STÄHELIN, D. et al. Distribuição espacial do banco de sementes de plantas daninhas em área de monocultura de feijão. Revista Biotemas, v. 22, n. 4, 2009.

VISMARA, L. S.; OLIVEIRA, V. A.; KARAM, D. Revisão de modelos matemáticos da dinâmica do banco de sementes de plantas daninhas em agrossistemas. Planta Daninha, v. 25, n. 1, p. 1-11, 2007.

VOLL, E.; ADEGAS, F. S.; GAZZIERO, D. L. P. Importância dos estudos de banco de sementes na ciência das plantas daninhas. In: CONGRESSO BRASILEIRO DA CIÊNCIA DAS PLANTAS DANINHAS, 27., 2010, Ribeirão Preto. Anais... Londrina, PR: SBCPD, 2010

VOLL, E.; GAZZIERO, D. L. P.; KARAM, D. Dinâmica de populações de Brachiaria plantaginea (Link) Hitchc. sob manejos de solo e de herbicidas. I. Sobrevivência. Pesq. Agropec. Bras., v. 30, n. 12, p. 1387-1396, 1995.

YANAGIZAWA, Y. A. N. P.; MAIMONI-RODELLA, R. C. S. Composição florística e estrutura da comunidade de plantas do estrato herbáceo em áreas de cultivo de árvores frutíferas. Planta Daninha, v. 17, n. 3, p. 459-468, 1999.

Recebido em: 08 de novembro de 2013

Aceito em: 15 de novembro de 2013 